\section{Rekayasa desain geometrik track sirkuit pada proyek perencanaan sirkuit road race km. 9 Bumi Rahayu dalam rangka akselerasi prestasi atlet balap motor Kabupaten Bulungan}

\section{Arfiadi Meidiansyah, ST}

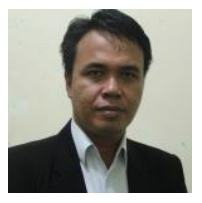

Penulis lahir di Surabaya ,02 Mei 1971 merupakan Alumni Fakultas Teknik Universitas Lambung Mangkurat pada tahun 1997, berprofesi sebagai tenaga ahli pada konsultan dan kontraktor dan saat ini sedang menempuh pendidikan profesi keinsinyuran di PS-PPI ULM..

buletinppi@ulm.ac.id
Pada Perencanaan Sirkuit Road Race KM.9 Bumi Rahayu Kabupaten Bulungan, track engineer yang bertanggungjawab melakukan rekayasa desain geometrik lintasan balap motor (road race) mendapat tugas mendesain lintasan balap dengan salah satu syarat pada kontrak kerja perencanaan adalah output dari produk yang dihasilkan berupa desain track/ lintasan balap harus mampu mengakselerasi kemampuan dan prestasi atlet balap lokal. Rekayasa desain geometrik yang dilakukan cukup sulit karena standarisasi yang sangat minim dan belum ada penelitian tentang geometrik lintasan balap untuk keperluan mendukung akselerasi kemampuan dan prestasi atlet balap. Dengan melakukan pendekatan dari sisi keolahragaan dan mengaplikasikannya pada sisi teknik sipil (rekayasa desain geometrik lintasan), hasil desain dapat memenuhi yang disyaratkan sesuai hasil sampling kepada atlet balap lokal yang berlatih di Sirkuit Bumi Rahayu.

www.buletinppi.ulm.ac.id

\section{Pendahuluan}

Kabupaten Bulungan yang sebelumnya merupakan bagian dari Provinsi Kalimantan Timur, sejak tahun 2005 mulai berbenah untuk dapat bersaing dengan daerah lainnya di Indonesia, termasuk dibidang olahraga prestasi yang pada saat itu sangat tertinggal dibandingkan kabupaten/kota lainnya di Kalimantan Timur, sehingga Pemerintah Kabupaten Bulungan merasa perlu melakukan akselerasi prestasi atlet lokal sesuai cabang olahraga yang ada di Kabupaten Bulungan bersama Komite Olahraga Nasional Indonesia (KONI) Kabupaten Bulungan dan instansiintansi terkait di Pemerintahan Kabupaten Bulungan. Program percepatan (akselerasi) kemampuan atlet, khususnya terkait kemampuan teknis atlet sesuai bidang olahraganya mulai dilaksanakan di Kabupaten Bulungan, dimana dalam pelaksanaannya membutuhkan prasarana latihan berupa venue latihan yang sekaligus juga dapat digunakan untuk venue kejuaraan. Salah satu cabang olahraga yang menjadi bagian daripada program tersebut adalah cabang olahraga balap motor (road race), dengan salah satu programnya melaksanakan pembangunan venue latihan dan kejuaraan berupa sirkuit road race yang perencanaan beberapa fasilitasnya mulai dilaksanakan pada tahun 2005 dan rencana lintasan balapnya mulai digarap pada tahun 2008 dengan mengacu pada regulasi PP.IMI tahun 2008.

Track engineer mendapat tugas untuk melakukan rekayasa desain pada bagian infrastruktur sirkuit road race yang menjadi kunci utama untuk akselerasi peningkatan kemampuan dan prestasi atlet balap lokal yaitu pada track/lintasan balap.
Tujuan dari rekayasa desain geometrik lintasan ini adalah :

Merencanakan desain track/lintasan sirkuit balap motor yang bertujuan untuk mengakselerasi kemampuan dan prestasi atlet balap lokal Kabupaten Bulungan.

Hasil tulisan ini juga diharapkan dapat :

1. Menjadi bahan masukan untuk penerapan ilmu ketekniksipilan dalam merencanakan lintasan sirkuit balap motor standar nasional oleh pihakpihak terkait.

2. Bahan masukan bagi perencana lintasan balap motor standar nasional yang ditujukan untuk percepatan peningkatan kemampuan dan prestasi atlet.

\section{Hasil Kerja}

\section{Gambaran Umum Hasil Desain Lintasan Balap Motor}

Rekayasa desain geometrik track / lintasan balap di lahan rencana Sirkuit KM.9 Bumi Rahayu dengan kondisi lahan berbukit mengutamakan efisiensi biaya konstruksi jalan / lintasan , sehingga dalam menentukan layout lintasan mempertimbangkan topografi lahan (meminimalisasi cut and and fill) dan memperhatikan kondisi tanah asli dari hasil soil investigation.

Merekayasa lintasan balap motor yang bertujuan mengakselerasi kemampuan dan prestasi atlet balap motor memiliki tantangan yang cukup besar karena 
sampai saat ini belum ada standar maupun penelitiannya yang dipublikasikan.

Untuk konstruksi lintasan balap mengacu pada standar Bina Marga (konstruksi lintasan tidak termasuk lingkup bahasan) dan desain geometrik lintasan mengacu pada regulasi yang dikeluarkan oleh PP.IMI dalam Standar Sirkuit Balap Motor Nasional (Standart of Road Race Circuit - SRRC) tahun 2008 yang memiliki banyak perbedaan dengan standar geometrik jalan raya, namun untuk geometrik horizontal tikungan tetap mengacu pada dasar teori geometrik jalan pada tikungan, khususnya tikungan full circle tetap digunakan dalam perhitungan.

Secara umum terdapat 2 jenis karakteristik lintasan balap motor skala nasional yaitu :

1. Rolling round, yaitu lintasan dengan kecepatan rata-rata tinggi pada setiap section lintasannya sesuai kapasitas motor yang digunakan pada lintasan sirkuit tersebut,

2. Stop and Go, yaitu lintasan dengan kecepatan ratarata sedang, banyak section lintasan yang memaksa pembalap menggunakan kecepatan yang sangat rendah,

Perhitungan alinyemen horizontal geometrik lintasan balap pada bagian tikungan menggunakan formula tikungan jenis full circle pada perencanaan geometrik jalan raya sebagai berikut :

$\mathrm{Tc}=\mathrm{R} \cdot \operatorname{tg} 1 / 2 \Delta$

$\mathrm{Ec}=\mathrm{T} \cdot \operatorname{tg} 1 / 4 \Delta$

$\mathrm{Lc}=(\Delta \pi / 180) \cdot \mathrm{R}$

$\mathrm{R}=$ radius tikungan (meter)

$\mathrm{Lc}=$ panjang tikungan (meter)

Syarat utama dimensi daripada lintasan balap motor sesuai aturan yang diterbitkan oleh PP.IMI tahun 2008 adalah :

Panjang total lintasan balap minimal $=1.200$ Meter Lebar lintasan balap minimal $=6$ Meter Lebar lintasan pada area start minimal $=8-10$ Meter

Sedangkan syarat-syarat teknis yang perlu diperhatikan terkait geometrik lintasan balap sesuai regulasi yang dikeluarkan PP.IMI tahun 2008 :

1. Kemiringan melintang jalan/lintasan maksimal $1,2 \%$.

2. Kemiringan memanjang jalan (long section) $2 \%$.

3. Untuk kombinasi antar dua tikungan yang berlawanan arah (chicane), diantaranya harus terdapat track lurus sepanjang minimal 18 Meter.

4. Tidak terdapat superelevasi pada tikungan seperti pada geometrik jalan raya.
5. Kecepatan rencana pada tikungan sesuai tabel pada SRRC Tahun 2008 PP. IMI (ket : tabel hanya mewakili beberapa ukuran radius tikungan saja)

Sampai saat ini belum ada standar acuan maupun literatur yang dapat langsung diaplikasikan dalam merencanakan geometrik lintasan balap motor untuk kepentingan percepatan peningkatan kemampuan dan prestasi atlet balap motor. Untuk itu perencana perlu melakukan analisis dari sisi keolahragaan yang hasilnya kemudian diterapkan pada sisi teknik sipil dengan point-point utama hasil desain adalah :

1. Mendesain lintasan sirkuit dengan total panjang $1.398 \mathrm{M}$ (memenuhi syarat minimal panjang $\geq$ $1.200 \mathrm{M})$

2. Menempatkan satu track / lintasan lurus panjang (>250M).

3. Membuat handicap dengan menempatkan kombinasi 2 tikungan berlawanan arah (chicane) dengan karakteristik perlambatan kecepatan.

4. Membuat handicap dengan menempatkan 2 radius tikungan dalam 1 tikungan searah.

5. Membuat tikungan arah kanan lebih banyak dari arah kiri (arah kanan 8 buah dan arah kiri 5 buah)

6. Membuat tikungan-tikungan tunggal / satu radius dengan berbagai panjang tikungan dan ukuran radius sesuai jenis/kapasitas motor yang akan digunakan.

\section{Dasar Acuan dan Kerangka Berpikir}

Desain rencana lintasan balap motor Sirkuit KM.9 Bumi Rahayu Kabupaten Bulungan berdasarkan :

1. Syarat-syarat dalam kontrak kerja perencanaan (RKS)

2. Standar Sirkuit Balap Motor Nasional yang dikeluarkan PP. IMI Tahun 2008

Rekayasa desain geometrik lintasan balap motor sirkuit Bumi Rahayu ini dengan memperhatikan point utama dalam kontrak kerja perencanaan Sirkuit Road Race dan Motocross KM. 9 Bumi Rahayu Kabupaten Bulungan yaitu :

1. Hasil desain lintasan balap motor harus mampu mengakselerasi peningkatan kemampuan dan prestasi atlet balap motor (road race) Kabupaten Bulungan.

2. Sirkuit / lintasan balap harus lolos homologasi nasional dari PP. IMI dan dapat menggelar Kejuaraan Nasional Resmi.

Untuk dapat lolos homologasi nasional sirkuit merupakan hal yang jauh lebih mudah karena cukup dengan memenuhi syarat-syarat geometric lintasan yang tertuang dalam aturan yang dikeluarkan oleh PP. IMI dan memenuhi kaidah-kaidah standar perencanaan, namun untuk merekayasa desain track / lintasan balap agar mampu mengakselerasi 
peningkatan kemampuan dan prestasi atlet balap lokal merupakan tantangan besar bagi pelaksanaan profesi keinsinyuran penulis yang diberi tugas merekayasa desain lintasan balap.

Untuk dapat memenuhi syarat-syarat tersebut, maka penulis melakukan pendekatan dan analisis dari sisi keolahragaan yang kemudian dituangkan dalam bidang ke-tekniksipil-an untuk merekayasa desain lintasan balap motor dengan memenuhi syarat-syarat desain lintasan sirkuit balap motor yang dikeluarkan PP.IMI.

Data-data untuk analisis sisi keolahragaan diperoleh dari studi literatur berupa :

1. Buku-buku keolahragaan terkait peningkatan prestasi dan psikologi olahraga (sport science).

2. Materi hasil diklat pelatih balap motor yang pernah diikuti penulis sebelumnya.

3. Pernyataan-pernyataan atlet balap dunia pada siaran televisi dan pernyataan pembalap lokal dan nasional (wawancara).

4. Data permasalahan atlet balap motor KON Kabupaten Bulungan.

Tahapan yang dilakukan penulis pada rekayasa lintasan balap motor sirkuit Bumi Rahayu adalah sebagai berikut :

1. Pengumpulan data-data dan penggunaannya.

Meliputi :

a. Data topografi lahan rencana sirkuit dan soil investigation, untuk efisiensi biaya konstruksi jalan/lintasan (cut-fill minimal), diperoleh dari survey lapangan,

b. Data motor yang digunakan untuk kejuaraan nasional dan regulasinya, sebagai bahan masukan dalam membuat lintasan berkarakteristik rolling round, diperoleh dari aturan PP. IMI,

c. Data kecepatan motor yang digunakan pada kejuaraan nasional pada sirkuit-sirkuit standar nasional / internasional di Indonesia, untuk mengetahui kecepatan tertinggi motor yang dipergunakan pada kejurnas balap motor, diperoleh dari survey, dan

d. Data-data dari sisi keolahragaan, diperoleh dari studi literatur, digunakan untuk merekayasa handicap pada sirkuit agar mampu memberikan percepatan (akselerasi) peningkatan kemampuan dan prestasi atlet lokal.

2. Analisis yang dilakukan

Untuk memenuhi kriteria terkait efisiensi biaya konstruksi pada kontrak kerja, maka tahapan analisis yang dilakukan adalah :

a. Melakukan analisa terhadap topografi lahan dan ketersediaan lahan sesuai rencana posisi letak lintasan balap pada Sirkuit Bumi Rahayu dan memilih bentuk jalur dengan jumlah cut and fill tanah yang sedikit,

b. Melakukan analisa terhadap hasil survey soil investigation agar jalur rencana lintasan berada pada tanah dengan kondisi daya dukung yang baik.

Hasil analisa diatas dituangkan dalam bentuk draft layout desain lintasan yang merupakan kerangka awal rencana layout jalur lintasan pada lahan yang tersedia.

Untuk memenuhi tujuan utama pembangunan sirkuit KM.9 Bumi Rahayu Kabupaten Bulungan yang mampu mengakselerasi peningkatan kemampuan dan prestasi atlet balap motor Kabupaten Bulungan, maka diperlukan desain track / lintasan yang :

1. Dapat meningkatkan kemampuan teknik (skill) balap atlet.

2. Dapat memberikan keuntungan / nilai lebih bagi atlet balap lokal agar dapat menjadi juara di Sirkuit Bumi Rahayu.

Memenuhi kedua point diatas perlu pendekatan dari sisi keolahragaan dengan terlebih dahulu mengetahui kondisi kelemahan atlet balap lokal sesuai data dari hasil monitoring dan evaluasi (monev) terhadap atlet KONI Kabupaten Bulungan, secara umum kelemahan atlet olahraga Kabupaten Bulungan, khususnya cabang olahraga balap motor terletak pada kemampuan teknik dan mental (sport psychology).

Hasil dari studi literatur terkait teori dan hasil penelitian tentang pembinaan prestasi atlet baik dari sisi teknis keolahragaan maupun psikologi olahraga (sport psychology) diperoleh bahwa :

1. Kemampuan penguasaan teknik/skill ke-cabor-an atlet diperoleh melalui latihan yang berulang pada materi latihan dengan "tingkat kesulitan yang komplit",

2. Kemampuan atlet dapat dipresentasikan dengan maksimal apabila faktor psikologis atlet mendukung,

3. Keberhasilan meraih kemenanganan (juara), khususnya tanding kandang sangat menunjang peningkatan sisi psikologis atlet pada kejuaraan berikutnya, baik di kandang maupun diluar.

Selain itu juga dengan mengumpulkan input pembalap lokal dan nasional (wawancara) serta pernyataan para pembalap dunia yaitu : Michael Doohan (1997), Max Biaggi (2005) dan Alm. Shoya Tomizawa (2006), dengan point inti yang menjadi masukan yaitu : "Sangat sulit menentukan racing line terbaik untuk mencapai kecepatan terbaik (maksimal) pada kombinasi tikungan dengan racing line yang berbeda dan kecepatan maksimal pada masing-masing tikungan tidak kontinyu".

( ket : Racing line adalah garis lintasan semu yang dilintasi pembalap pada lintasan balap (track) untuk mendapatkan kecepatan maksimum saat melintas). 
Pendekatan sisi keolahragaan diatas diterjemahkan menjadi elemen-elemen geometrik pada track / lintasan dengan :

1. Melengkapi lintasan dengan tikungan-tikungan berbagai variasi ukuran panjang tikungan dan variasi ukuran radius tikungan yang masih sesuai dengan kecepatan motor balap rencana yang akan digunakan di sirkuit Bumi Rahayu dengan tujuan untuk dapat meningkatkan kemampuan teknik (skill) atlet melalui latihan rutin / berulang,

2. Melengkapi lintasan dengan handicaps khusus yang mampu memberikan nilai lebih atau keuntungan bagi atlet balap motor lokal saat kejuaraan di lintasan sirkuit Bumi Rahayu.

Handicaps khusus yang dibuat untuk membuat racing line berkarakter non-kontinyuitas yaitu dengan menempatkan :

1. Kombinasi tikungan berbeda arah (chicane) dengan menempatkan radius yang lebih besar pada tikungan pertama dan dilanjutkan tikungan radius kecil arah berbeda (memerlukan perlambatan), dan diantara kedua tikungan ditempatkan lintasan lurus sepanjang 20 Meter untuk memenuhi syarat SRRC tahun 2008 yang dikeluarkan PP.IMI bahwa antar tikungan yang berbeda arah harus terdapat lintasan lurus minimal 18 meter.

2. Menempatkan 2 (dua) radius tikungan searah dalam satu tikungan berupa radius tikungan lebih besar yang digabung dengan radius tikungan yang lebih kecil, sehingga dalam satu tikungan terdapat $1 / 2$ panjang lengkung awal tikungan yang berbeda dengan $1 / 2$ panjang lengkung sisanya , tikungan jenis ini dalam SRRC tahun 2008 yang dikeluarkan PP. IMI tidak dilarang.

\section{Hasil Desain dan Pembahasan}

Rencana draft layout lintasan dibuat sesuai dengan rencana tata letak lintasan balap motor dan ketersediaan lahan dan data topografi lahan serta pertimbangan volume cut fill dan hasil soil investigation.

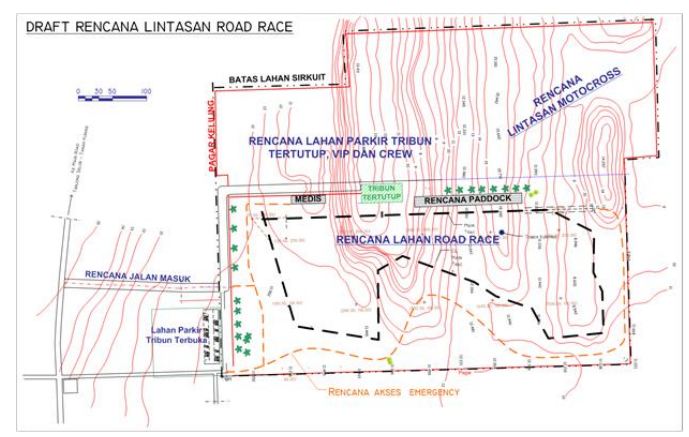

Gambar 1. Rencana draft layout lintasan
Radius tikungan dan kecepatan rencana maksimum tikungan pada lintasan balap motor diambil menggunakan tabel regulasi pada SRRC Tahun 2008 yang dikeluarkan PP.IMI yang juga mengacu pada regulasi Federation International Motorsport (FIM), sebagai berikut :

Tabel 1. Radius - Kecepatan Rencana

\begin{tabular}{|c|c|c|c|c|c|c|c|}
\hline $\mathbf{R}(\mathbf{M})$ & 25 & 50 & 100 & 150 & 200 & 250 & 300 \\
\hline $\begin{array}{c}\text { V } \\
\text { (KM/H) }\end{array}$ & 75 & 105 & 140 & 167 & 190 & 210 & 230 \\
\hline
\end{tabular}

(Sumber : SRRC PP.IMI Point 029.2.2.)

Tabel kecepatan diatas adalah untuk standar motor balap tertinggi (saat itu MotoGP 500CC - 2 stroke engine), sedangkan kecepatan maksimal pada event Kejurnas pada table berikut :

Tabel 2. Kelas Tanding Kejurnas dan Kecepatan Maksimum

\begin{tabular}{|c|c|}
\hline Kelas & Vmax (Km/h) \\
\hline MP1 & 125 s/d 140 \\
\hline MP2 & \multirow{2}{*}{120 s/d 125} \\
\hline MP4 & \multirow{2}{*}{105 s/d 115} \\
\hline MP5 & \\
\hline
\end{tabular}

(Sumber : hasil survey)

Untuk menentukan berbagai kecepatan dan radius tikungan sesuai kecepatan motor rencana perlu dilakukan pendekatan melalui regresi dari nilai-nilai pada table regulasi (table 1 ).

Dengan bantuan software curve expert 1.4 diperoleh model regresi yang hasilnya paling mendekati yaitu :

Hoerl Model (power law family)

$\mathrm{Y}=\mathrm{a} \cdot \mathrm{b}^{\mathrm{X}} \cdot \mathrm{X}^{\mathrm{c}}$

Dan koefisien :

$\mathrm{a}=1.91837543097 \mathrm{E}+001$

$b=1.00012027807 E+000$

$c=4.28607912743 \mathrm{E}-001$

dengan :

$\mathrm{V}=\mathrm{Y}=$ Kecepatan Maksimum (KM/H)

$\mathrm{R}=\mathrm{X}=$ Radius Tikungan $(\mathrm{M})$

Dengan output grafik pada gambar sebagai berikut :

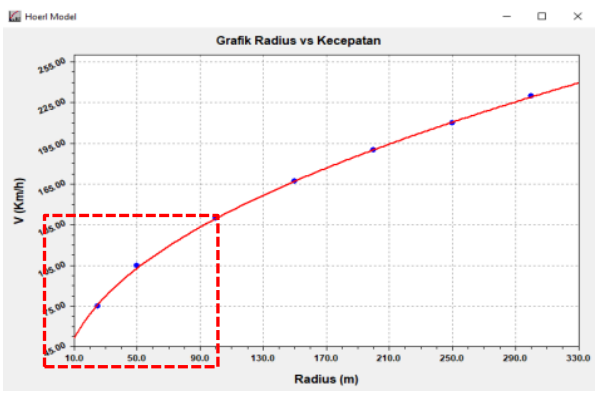


Gambar 2. Grafik Pendekatan Radius dan kecepatan pada tikungan (Sumber : hasil perhitungan)

(keterangan : garis putus-putus pada grafik adalah area batasan kecepatan/radius yang digunakan sesuai kecepatan motor rencana).

Arah tikungan (corners direction) diperbanyak arah kanan (right-hand corner), hal ini sesuai dengan hasil wawancara dengan atlet balap lokal dan luar Kabupaten Bulungan yang menyatakan bahwa bahwa tikungan arah kanan lebih sulit dilakukan daripada tikungan arah kiri.

Rencana draft layout lintasan yang telah ditentukan sebelumnya (pertimbangan efisiensi biaya konstruksi) disempurnakan dengan menempatkan berbagai tikungan yang telah didetailkan ukuran-ukurannya, baik radius tikungan maupun panjang tikungan, sebagai berikut :

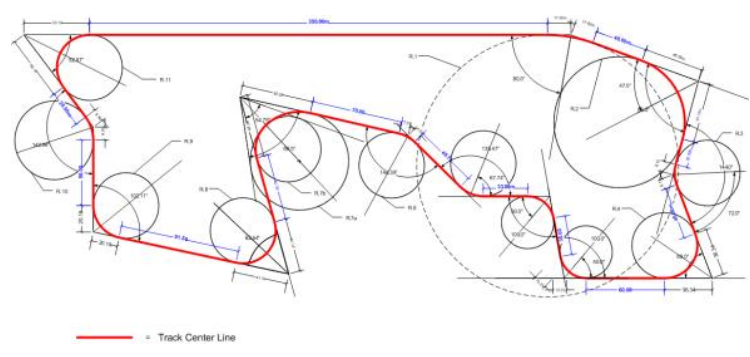

Gambar 3. Penempatan dan pendetailan tikungan

Dan melengkapi layout lintasan dengan dimensional yang sesuai persyaratan dari PP.IMI, sehingga layout lintasan seperti pada gambar berikut:

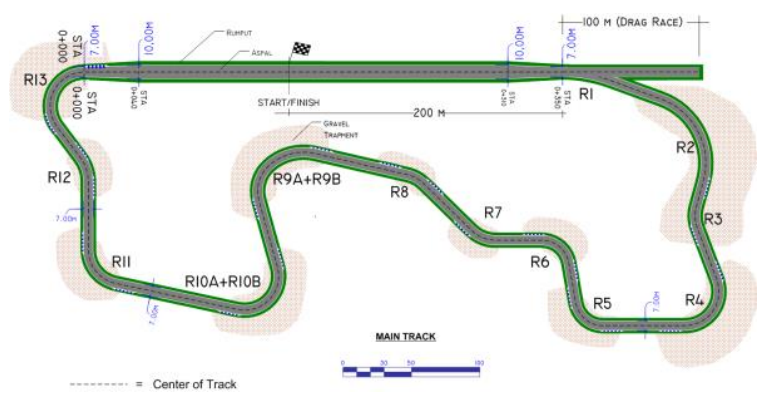

Gambar 4. Desain lintasan balap motor Sirkuit Bumi Rahayu

Handicap khusus dengan menggabungkan 2 radius tikungan dalam 1 buah tikungan arah kiri dengan detail

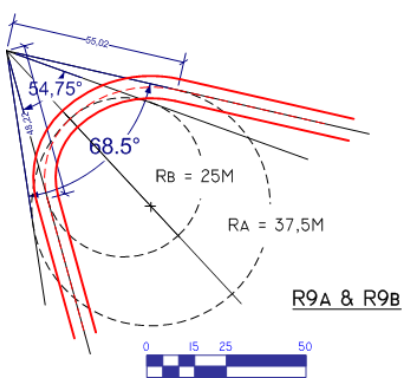

Gambar 5. Desain Komposisi 2 Tikungan searah digabung.

Dan handicap khusus dengan dua tikungan berbeda arah (chicane) dengan track lurus sepanjang 20 Meter (syarat dalam SRRC Tahun 2008 - PP.IMI minimal 18 M) :

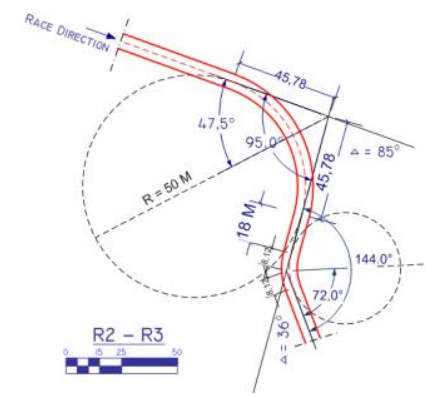

Gambar 6. Desain Chicane (R2-R3)

Chicane yang dikombinasi dengan tikungan sebelumnya (tikungan R1) untuk mengacaukan racing line umum yang biasanya diambil pembalap saat memasuki tikungan. Tikungan R1 dikombinasi dengan chicane $(\mathrm{R} 2+\mathrm{R} 3)$ merupakan satu kesatuan problem set yang saling mendukung.

Pembalap cenderung akan mengambil jalur racing line yang umum diambil saat bersiap (approach) sebelum memasuki tikungan R1 yaitu sisi luar lintasan lurus, dan mengambil sisi dalam lintasan saat di puncak radius tikungan R1 serta diakhiri di sisi luar lintasan pada akhir tikungan R1. Penggunaan jalur ini akan memberikan keleluasaan melaju pada kecepatan tertinggi, namun akan bermasalah pada saat akan memasuki tikungan R2 dan R3 dikarenakan radius R2 yang lebih kecil dan R3 yang jauh lebih kecil lagi yang memaksa pembalap memperlambat kecepatan untuk memenuhi kecepatan rencana maksimal tikungan R2 disaat motor pada posisi miring/menikung dengan kecepatan tertinggi setelah melewati tikungan R1 (dapat menyebabkan keluar lintasan atau terjatuh karena kehilangan grip antara ban dan aspal).

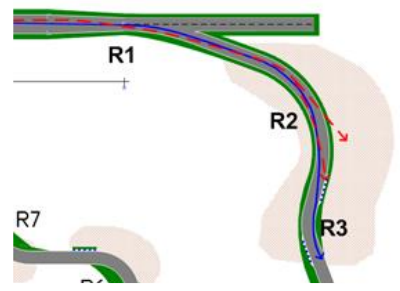


Gambar 7. Racing Line Kombinasi R1 + Chicane (R2-R3) Secara keseluruhan geometric technical data of the road race track seperti pada tabel berikut :

Tabel 3. Race Track Axis

\begin{tabular}{|c|c|c|c|}
\hline $\begin{array}{c}\text { Crook } \\
n^{\circ}\end{array}$ & Radius(M) & Length(M) & Type \\
\hline & & 350,00 & Straightaway \\
\hline \multirow[t]{2}{*}{ R1 } & 100 & 34,89 & $\begin{array}{l}\text { Right hand } \\
\text { corner }\end{array}$ \\
\hline & & 40,00 & Straightaway \\
\hline \multirow[t]{2}{*}{$\mathrm{R} 2$} & 50 & 74,14 & $\begin{array}{l}\text { Right hand } \\
\text { corner* }\end{array}$ \\
\hline & & 20,00 & Straightaway* \\
\hline \multirow[t]{2}{*}{ R3 } & 25 & 15,70 & $\begin{array}{l}\text { Left hand } \\
\text { corner* }\end{array}$ \\
\hline & & 40,00 & Straightaway \\
\hline \multirow[t]{2}{*}{ R4 } & 25 & 48,42 & $\begin{array}{c}\text { Right hand } \\
\text { corner }\end{array}$ \\
\hline & & 60,00 & Straightaway \\
\hline \multirow[t]{2}{*}{ R5 } & 20 & 27,91 & $\begin{array}{l}\text { Right hand } \\
\text { corner }\end{array}$ \\
\hline & & 30,00 & Straightaway \\
\hline \multirow[t]{2}{*}{ R6 } & 30 & 27,91 & Left hand corner \\
\hline & & 33,88 & Straightaway \\
\hline \multirow[t]{2}{*}{ R7 } & 25 & 19,42 & $\begin{array}{l}\text { Right hand } \\
\text { corner }\end{array}$ \\
\hline & & 48,79 & Straightaway \\
\hline \multirow[t]{2}{*}{$\mathrm{R} 8$} & 35 & 13,79 & Left hand corner \\
\hline & & 70,00 & Straightaway \\
\hline R9.a & 37,5 & 36,47 & \multirow{2}{*}{ Left hand corner } \\
\hline \multirow[t]{2}{*}{ R9.b } & 25 & 27,31 & \\
\hline & & 50,75 & Straightaway \\
\hline \multirow[t]{2}{*}{ R10 } & 25 & 51,23 & $\begin{array}{l}\text { Right hand } \\
\text { corner }\end{array}$ \\
\hline & & 91,50 & Straightaway \\
\hline \multirow[t]{2}{*}{ R11 } & 25 & 33,97 & $\begin{array}{l}\text { Right hand } \\
\text { corner }\end{array}$ \\
\hline & & 50,00 & Straightaway \\
\hline \multirow[t]{2}{*}{$\mathrm{R} 12$} & 30 & 18,87 & Left hand corner \\
\hline & & 28,50 & Straightaway \\
\hline R13 & 25 & 55,40 & $\begin{array}{l}\text { Right hand } \\
\text { corner }\end{array}$ \\
\hline
\end{tabular}

* chicane (syarat : track lurus diantaranya minimal 18M)

(Sumber : perhitungan / hasil desain perencanaan)

Length straightaways $=485,40 \mathrm{M}(65 \%)$

Length of the corners $=913,42 \mathrm{M}(35 \%)$

Total $=1.398,82 \mathrm{M}$

Right-hand corners $=8$

Left-hand corners $=5$

Straigthaway (at Starting line) width $=10 \mathrm{M}$

Race track width

$=7 \mathrm{M}$ (keterangan : SRRC-2008- PP.IMI lebar lintasan balap minimum $=6 \mathrm{M} \&$ panjang $1.200 \mathrm{M})$.

Pada bagian lintasan lurus terpanjang ( $L=350 \mathrm{M}$ ) dibuat penambahan panjang lintasan sebesar 100 meter diluar lintasan utama polygon tertutup agar juga dapat digunakan untuk balap drag (drag race).

\section{Sampel Atlet Balap dan Hasli Prestasinya}

Setelah lintasan balap (race track) sirkuit Bumi Rahayu selesai pembangunan fisiknya melalui pekerjaan Tahap I pada tahun 2010, meskipun pekerjaan pembangunan fasilitas diluar track (paddock, tribun terbuka, pagar, lahan parkir, dll) masih dalam tahap pengerjaan, namun kegiatan latihan atlet dan kejuaraan mulai dilaksanakan.

Untuk dapat mengetahui keberhasilan rekayasa yang dilakukan pada desain lintasan balap motor Sirkuit Bumi Rahayu ini maka dilakukan sampling terhadap 4 (empat) pembalap lokal yang terdiri dari 3 sampel yang mewakili 3 kategori.

Tabel 4. Data Teknis Person Sampel

\begin{tabular}{|c|c|c|}
\hline Sampel 1 & Sampel 2 & Sampel 3 \\
\hline $\begin{array}{l}1 \text { pembalap, } \\
\text { efektif } \\
\text { diprogram } \\
\text { sejak } 2011\end{array}$ & $\begin{array}{l}1 \text { pembalap, } \\
\text { efektif } \\
\text { diprogram sejak } \\
2013\end{array}$ & $\begin{array}{l}2 \text { pembalap, } \\
\text { efektif } \\
\text { diprogram } \\
\text { sejak 2011, } \\
\text { pernah } \\
\text { mengikuti } \\
\text { berbagai } \\
\text { kejuaraan }\end{array}$ \\
\hline $\begin{array}{l}\text { Dalam } \\
\text { Program } \\
\text { Puslatkab } \\
\text { KONI } \\
\text { Bulungan }\end{array}$ & $\begin{array}{l}\text { Dalam Program } \\
\text { Puslatkab KONI } \\
\text { Bulungan }\end{array}$ & $\begin{array}{l}\text { Dalam } \\
\text { Program } \\
\text { Puslatkab } \\
\text { KONI Bulungan }\end{array}$ \\
\hline $\begin{array}{l}\text { Pemula, dan } \\
\text { bukan } \\
\text { pembalap } \\
\text { jalanan } \\
\text { tidak pernah } \\
\text { berkendara } \\
\text { di jalan raya }\end{array}$ & $\begin{array}{l}\text { Pemula, sering } \\
\text { berkendara di } \\
\text { jalan raya }\end{array}$ & $\begin{array}{l}\text { Senior dan } \\
\text { pembalap } \\
\text { jalanan } \\
\text { /tingkat } \\
\text { keberanian } \\
\text { tinggi }\end{array}$ \\
\hline $\begin{array}{l}\text { Dilengkapi } \\
\text { PPA } \\
\text { (program } \\
\text { peningkatan } \\
\text { prestasi } \\
\text { atlet) }\end{array}$ & $\begin{array}{l}\text { PPA mengikuti } \\
\text { Sampel } 1\end{array}$ & Dilengkapi PPA \\
\hline $\begin{array}{l}\text { Diberi input } \\
\text { data Racing } \\
\text { Line sirkuit } \\
\text { Bumi Rahayu }\end{array}$ & $\begin{array}{l}\text { Mengikuti } \\
\text { Sampel } 1\end{array}$ & $\begin{array}{lr}\text { Tidak } & \text { diberi } \\
\text { input } & \text { data } \\
\text { Racing } & \text { Line } \\
\text { pada } & \text { track } \\
\text { sirkuit } & \end{array}$ \\
\hline
\end{tabular}


Atlet balap sampel 1 atas nama $M$. Febriansyah, sampel 2 atas nama Adhi Chandra dan sampel 3 terdiri dari 2 atlet balap lokal yang sebelumnya sudah lama mewakili Kabupaten Bulungan dalam berbagai event kejuaraan.

Dengan hasil capaian seperti pada grafik kemajuan progress atlet-atlet sampel di lintasan balap motor Sirkuit Bumi Rahayu sebagai berikut :

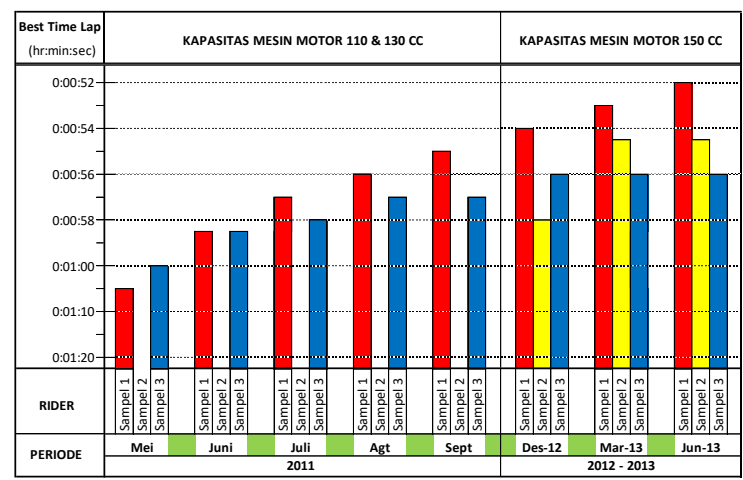

Gambar 8. Grafik peningkatan kemampuan atlet sampel (Sumber : Data Monev Binpres KONI Kab. Bulungan)

Hasil capaian prestasi atlet dengan grafik sebagai berikut :

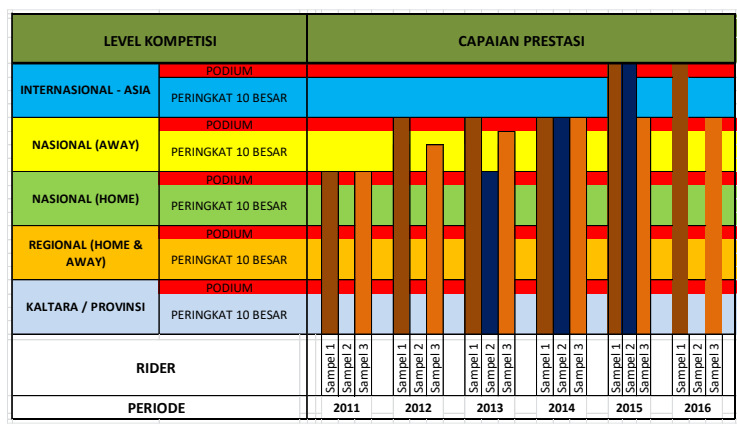

Gambar 9. Grafik prestasi atlet pada berbagai kejuaraan

(Sumber : KONI Bulungan dan Pelatih IMI Bulungan).

\section{Kesimpulan}

Rekayasa desain lintasan balap motor Sirkuit Bumi Rahayu dengan karakteristik rolling round serta berbagai variasi panjang dan radius tikungan yang dilengkapi beberapa handicap khusus mampu mengakselerasi kemampuan dan prestasi atlet balap lokal yang berlatih di lintasan tersebut, dengan capaian prestasi sampai tingkat Asia (memenuhi syarat dan tujuan pembangunan sirkuit).

\section{Ucapan Terimakasih}

Ucapan terimakasih disampaikan kepada :

1. Dekan Fakultas Teknik ULM dan Ketua Jurusan Program Studi PS-PPI ULM.

2. Dr.Ir. Rusdiansyah,ST.,MT.,IPM, selaku Dosen Pembimbing.

3. Bapak H. Budiman Arifin selaku Bupati Bulungan yang peduli dengan kemajuan olahraga di Kabupaten Bulungan.

4. Bambang Gunardi selaku homologator PP. IMI tahun 2008 yang telah memberikan banyak masukan.

5. H. Saleh Pangeran Khar, ST selaku Ketua Umum KONI Kabupaten Bulungan periode 2010-2014 dan 2014-2018.

\section{Referensi}

1 Pengurus Pusat Ikatan Motor Indonesia (PP.IMI), Standar Sirkuit Balap Motor Nasional / Standart of Road Race Circuit (2008) : 1-30

2 Silvia Sukirman, Dasar-dasar perencanaan geometrik jalan (1999) : 125-128

3 Singgih Gunarsa, Psikologi olahraga prestasi (2008) : 23-35, 52-65, 108-113

4 Suryanto, Pengaruh mental imagery bagi atlet dalam meraih prestasi (2008)

5 KONI Kab Bulungan, Laporan hasil monitoring dan evaluasi (monev) latihan rutin atlet KONI Bulungan (2011), (2012), (2013), (2014), (2014), 2015

6 Arfiadi Meidiansyah, Data bidang binpres KONI Kabupaten Bulungan : atlet berprestasi Kabupaten Bulungan tahun 2012 - 2016 (2016). 